\title{
Birth Prevalence of Overt Congenital Anomalies in Kano Metropolis: Overt Congenital Anomalies in the Kano
}

\author{
Lofty-John Chukwuemeka Anyanwu ${ }^{1,2, *}$, Barnabas Danborno ${ }^{1}$, Wilson O. Hamman ${ }^{1}$ \\ ${ }^{1}$ Department of Human Anatomy, Ahmadu Bello University Zaria, Nigeria \\ ${ }^{2}$ Paediatric Surgery Unit, Department of Surgery Aminu Kano Teaching Hospital and Bayero University Kano, Nigeria
}

Copyright (C) 2015 Horizon Research Publishing All rights reserved.

\begin{abstract}
Congenital anomalies are abnormalities of prenatal origin, and their prevalence varies worldwide. The objective of this study was to determine the prevalence and spectrum of overt congenital anomalies in live born neonates in selected hospitals in the Kano metropolis of North western Nigeria, as well as the associated maternal, paternal and neonatal risk factors. A descriptive study design was employed. All live born neonates in three major hospitals in Kano metropolis were prospectively studied from April 2013 to December 2013. Detailed family history and clinical data were recorded in a structured questionnaire for each child. A total of 1456 live born neonates were recruited into the study, of which 41 (28.15 per 1000 live births) had overt congenital malformations with $5(12.20 \%)$ having multiple system involvement and $36(87.80 \%)$ having a single system affectation. The most common system involved in neonates with isolated single system malformations were the central nervous system (10 cases) and the genitourinary system (10 cases). The consanguinity rate in the study was $17.83 \%$. Birth weight of the neonates had a significant but negative association with the likelihood of being born with a congenital malformation [OR $=0.374$; (95\% CI 0.196 0.711) $\mathrm{P}=0.003$ ]. Given the high frequency of potentially preventable central nervous system malformations in this study, emphasis on the primary prevention of congenital malformations by encouraging periconceptional use of folic acid containing multivitamin supplements is recommended.
\end{abstract}

Keywords Congenital malformation; Overt; Consanguinity; Periconceptional; Neonate

\section{Introduction}

Congenital malformations also known as birth defects are structural or functional anomalies of prenatal origin which result from a defect or abnormality in the process of development [1-4]. The birth prevalence of congenital anomalies varies from country to country. It is believed that between $2-4 \%$ of live born infants and $15-20 \%$ of stillbirths have a significant birth defect $[5,6,7]$. Birth defects are an important cause of childhood morbidity and mortality as it is estimated that one out of every 3 babies that die in the world has a congenital anomaly $[7,8]$.

The World Health Organization (WHO) estimates that about 260,000 deaths worldwide (i.e. $7 \%$ of all neonatal deaths) were caused by congenital anomalies in the year 2004 [9]. Apart from the direct impact on affected children and their families, congenital anomalies exert an enormous financial burden on a nation's health, educational and social support services $[2,10]$.

Congenital anomalies could be broadly classified into 2 major groups i.e. single system abnormalities affecting a single organ system or body part, and multiple abnormalities which affect more than one organ system or body part $[1,2,11]$. Major congenital anomalies are defined as those abnormalities that if uncorrected or uncorrectable will significantly impair normal body functions or reduce life expectancy, while minor anomalies are those that cause no handicap i.e. they cause no significant physical or functional effect and can be regarded as normal variants if they affect more than $4 \%$ of the population $[1,5]$.

Recorded prevalence rates for congenital anomalies in developing countries are underestimated by deficiencies in diagnostic capabilities, lack of reliability of medical records and health statistics, and underreporting [10]. In response to this concern, this study was undertaken to establish the prevalence and spectrum of overt congenital malformations at birth in the Kano metropolis in Northwestern Nigeria.

\section{Materials and Methods}

A study of 1456 consecutive live births at three major hospitals (Aminu Kano Teaching Hospital, Murtala Mohammed Specialist Hospital, and Sheikh Jidda Specialist Hospital) in the Kano metropolis of northwestern Nigeria. 
The study was carried out between April 2013 and December 2013.

Approval was obtained from the Teaching Hospital's and Kano State's ethical committees for this study. All babies were routinely examined within 48 hours of delivery [1]. The diagnosis of congenital abnormality was based only on clinical examination and assessment by trained research assistants who were either medically qualified or medical students. Chromosomal analysis and autopsies were not performed in this study. Both major and minor malformations were included in the study. Structural anomalies are considered "overt" or "external" when they are visible on inspection, otherwise they are considered "occult" or internal" $[4,12]$. In neonates with congenital anomalies involving two or more systems, a diagnosis was made if the group of malformations constitute a known syndrome or chromosomal disorder, and the child is recorded only once under that diagnosis. If no diagnosis can be made, the infant is classified and coded only once as having a multiple congenital abnormality, and the system with the most obvious or major malformation was noted $[7,13]$. For each case, a detailed pregnancy and family history, including the presence of absence of consanguinity, was obtained by interviewing the mother [1]. Data were recorded on a pretested structure questionnaire for each neonate. Data were analyzed using SPSS 15.0 (SPSS Inc, Chicago, IL).

Descriptive statistics were computed for continuous variables, while proportions were used for categorical characteristics of the study subjects. The chi-square test was used to test for association. Fisher's exact test (two-tailed) was used where appropriate. Multivariate logistic regression was done to identify significant predictors of being born with congenital anomaly. Level of significance was set at $\mathrm{P}<0.05$ for all tests.

\section{Results}

A total of 1456 live born neonates were recruited into the study over the study period.

The basic characteristics of the study neonates and their mothers (Table 1 and Table 2) are as depicted. Most of the neonates were males $(52 \% ; 757 / 1456)$, majority of them were products of singleton gestation $(91.62 \% ; 1334 / 1456)$. Vaginal delivery was the main type of delivery $(85.60 \%)$ in the study. A consanguinity rate of $17.83 \%$ was observed in the study.

During the study period, 41 babies were found to have an overt congenital malformation, giving a prevalence of 28.15 per 1000 live births (Table 3). Among those with a congenital malformation, $5(12.2 \%)$ had multiple abnormalities, while $36(87.8 \%)$ had involvement of a single system. The prevalence for multiple malformations in the study was thus 3.43 per 1000 live births, and that for single-system malformations was 24.72 per 1000 live births. Among the neonates with single-system malformations
(Table 3 and Table 4), the most common systems involved were the central nervous system and genitourinary system with 10 cases each, the dermatological system (6 cases), and gastrointestinal system (5 cases).

Table 1. Characteristics of Neonates in the Study

\begin{tabular}{ccc}
\hline Variables & Frequency & Percentage (\%) \\
\hline Gender & 757 & 52 \\
Male & 699 & 48 \\
Female & & \\
Type of Delivery & 1242 & 85.60 \\
Vaginal & 209 & 14.40 \\
Caesarean Section & & \\
Gestational Age (Weeks) & 363 & 25.55 \\
36 and above & 838 & 58.97 \\
$37-40$ & 220 & 15.48 \\
41 and above & & \\
Nature of Gestation & 1334 & 91.62 \\
Singleton & 116 & 7.97 \\
Twins & 6 & 0.41 \\
Triplets & & \\
Birth Weight (kg) & 98 & 7.42 \\
$<2.5$ & 1196 & 90.54 \\
$2.5-4.0$ & 27 & 2.04 \\
$>4.0$ & &
\end{tabular}

Table 2. Socio-demographic characteristics of neonates' mothers

\begin{tabular}{|c|c|c|}
\hline Variables & Frequency & Percentage $(\%)$ \\
\hline \multicolumn{3}{|l|}{ Age (Years) } \\
\hline 19 and below & 153 & 10.58 \\
\hline $20-34$ & 061 & 73.37 \\
\hline $35-39$ & 170 & 11.76 \\
\hline 40 and above & 62 & 4.29 \\
\hline \multicolumn{3}{|l|}{ Highest Level of Education } \\
\hline None & 25 & 1.72 \\
\hline Primary/Quaranic & 552 & 38.07 \\
\hline Secondary & 661 & 45.59 \\
\hline Post-Secondary & 212 & 14.62 \\
\hline \multicolumn{3}{|l|}{ Religion } \\
\hline Christianity & 68 & 4.68 \\
\hline Islam & 1382 & 95.11 \\
\hline Others & 3 & 0.21 \\
\hline \multicolumn{3}{|l|}{ Ethnic Group of Husband } \\
\hline Hausa/Fulani & 1312 & 90.30 \\
\hline Igbo & 21 & 1.45 \\
\hline Yoruba & 24 & 1.65 \\
\hline Others & 96 & 6.61 \\
\hline \multicolumn{3}{|l|}{ Nature of Marriage } \\
\hline Consanguineous & 256 & 17.83 \\
\hline Non- Consanguineous & 1180 & 82.17 \\
\hline \multicolumn{3}{|l|}{ Parity } \\
\hline 1 & 392 & 27.36 \\
\hline $2-4$ & 571 & 39.85 \\
\hline $5+$ & 470 & 32.80 \\
\hline \multicolumn{3}{|l|}{ Booking Status of Pregnancy } \\
\hline Booked & 1386 & 95.52 \\
\hline Unbooked & 65 & 4.48 \\
\hline \multicolumn{3}{|l|}{ Age of Husband (Years) } \\
\hline 19 and below & 0 & 0 \\
\hline $20-34$ & 498 & 35.98 \\
\hline $35-39$ & 309 & 22.11 \\
\hline 40 and above & 580 & 41.91 \\
\hline
\end{tabular}


Table 3. Summary of congenital malformations in the study

\begin{tabular}{ccc}
\hline Malformations & No. of Cases & $\begin{array}{c}\text { Prevalence Per } \\
1000 \text { Births }\end{array}$ \\
\hline Multiple Malformations & 2 & 1.37 \\
Syndromes & 3 & 2.06 \\
Undetermined & 5 & 3.43 \\
Sub-Total & & \\
Single-System & 10 & 6.87 \\
Malformations & 2 & 1.37 \\
Central nervous system & 5 & 3.43 \\
Mouth & 10 & 6.87 \\
Gastrointestinal & 3 & 2.06 \\
Genitourinary & 6 & 4.12 \\
Musculoskeletal & 36 & 24.72 \\
Dermatological & & \\
Sub-Total & 41 & 28.15 \\
Total & &
\end{tabular}

Table 4. Single-System involvement among neonates with congenital malformations

\begin{tabular}{|c|c|c|}
\hline & System & No. of Cases \\
\hline \multirow{6}{*}{ A. } & Central Nervous System & \\
\hline & Hydrocephalus & 2 \\
\hline & Anencephaly and encephalocoele & 1 \\
\hline & Encephalocoele & 1 \\
\hline & Microcephaly & 6 \\
\hline & Sub Total & 10 \\
\hline \multirow{3}{*}{ B. } & $\begin{array}{c}\text { Mouth } \\
\text { Cleft lip and palate }\end{array}$ & 1 \\
\hline & Cleft palate & 1 \\
\hline & Sub Total & 2 \\
\hline \multirow{5}{*}{ C. } & Gastrointestinal System & \\
\hline & Intestinal Obstruction & 2 \\
\hline & Omphalocoele & 1 \\
\hline & Gastroschisis & 2 \\
\hline & Sub Total & 5 \\
\hline \multirow{4}{*}{ D. } & Genitourinary System & \\
\hline & Bladder exstrophy/epispadias complex & 3 \\
\hline & Undescended testes & 7 \\
\hline & Sub Total & 10 \\
\hline \multirow{3}{*}{ E. } & Musculoskeletal System & \\
\hline & Polydactyly & 3 \\
\hline & Sub Total & 3 \\
\hline \multirow{4}{*}{ F. } & Dermatological & \\
\hline & Hyperpigmented patches & 6 \\
\hline & Sub Total & 6 \\
\hline & Total & 36 \\
\hline
\end{tabular}

Table 5. Multiple congenital abnormalities in the study

\begin{tabular}{|c|c|c|}
\hline & Malformations & $\begin{array}{l}\text { No. of } \\
\text { Cases }\end{array}$ \\
\hline \multirow{4}{*}{ A. } & Syndromes & \\
\hline & Down's & 1 \\
\hline & Beckwith - Wiedemann & 1 \\
\hline & Sub Total & 2 \\
\hline \multirow{6}{*}{ B. } & Undetermined & \\
\hline & Microcephalous and sacrococcygeal teratoma & \\
\hline & $\begin{array}{l}\text { Hydrocephalus, meningocoele and bilateral } \\
\text { talipes equinovarus }\end{array}$ & $\begin{array}{l}1 \\
1\end{array}$ \\
\hline & Cleft lip, cleft palate and polydactyly of both & 1 \\
\hline & $\begin{array}{c}\text { upper and lower limbs } \\
\text { Sub Total }\end{array}$ & 3 \\
\hline & Total & 5 \\
\hline
\end{tabular}

Of the 5 neonates with multiple malformations, 2 had recognized syndromes one of which was a case of Down's syndrome and the other a case of Beckwith - Wiedemann syndrome (Table 5). In 3 of these neonates with multiple malformations, a complete evaluation was not possible in order to determine whether they were syndromes, associations, sequences, complexes or chromosomal abnormalities. They were thus classified as "undetermined" (Table 5). The birth prevalence of Down's syndrome and Beckwith - Wiedemann syndrome in the study was 0.69 per 1000 live births each.

Table 6. Socio-demographic characteristics of neonates' mothers in relation to birth of a child with a congenital malformation

\begin{tabular}{|c|c|c|c|c|c|}
\hline \multirow[b]{2}{*}{$\begin{array}{l}\text { Background } \\
\text { characteristics }\end{array}$} & \multirow[b]{2}{*}{$\mathrm{n}$} & \multicolumn{2}{|c|}{$\begin{array}{c}\begin{array}{c}\text { Congenital } \\
\text { malformation }\end{array} \\
\end{array}$} & \multicolumn{2}{|c|}{$\begin{array}{c}\text { Statistical } \\
\text { significance }\end{array}$} \\
\hline & & Present & Absent & $x^{2}$ & $\mathrm{p}$-Value \\
\hline Age (Years) & & & & & \\
\hline 19 and below & 153 & 3 & 150 & 1.383 & 0.710 \\
\hline $20-34$ & 1061 & 29 & 1032 & & \\
\hline $35-39$ & 170 & 5 & 165 & & \\
\hline 40 and above & 62 & 3 & 59 & & \\
\hline \multicolumn{6}{|l|}{ Highest level of } \\
\hline $\begin{array}{c}\text { education } \\
\text { None }\end{array}$ & 25 & 0 & 25 & & \\
\hline Primary/Quaranic & 552 & 17 & 535 & 1.633 & 0.652 \\
\hline Secondary & 661 & 20 & $\begin{array}{r}641 \\
208\end{array}$ & & \\
\hline $\begin{array}{l}\text { Post -Secondary } \\
\text { Religion }\end{array}$ & & & & & \\
\hline Christianity & 68 & 2 & 66 & & \\
\hline Islam & 1382 & 39 & 1343 & 0.091 & 0.956 \\
\hline Others & 3 & 0 & 3 & & \\
\hline \multicolumn{6}{|l|}{ Ethnic group of } \\
\hline $\begin{array}{l}\text { husband } \\
\text { Hausa/Fulani }\end{array}$ & 1312 & 38 & 1274 & & \\
\hline Igbo & 21 & 1 & 20 & 1203 & 0752 \\
\hline $\begin{array}{l}\text { 1goo } \\
\text { Yoruba }\end{array}$ & 24 & 0 & 24 & 1.203 & 0.152 \\
\hline Others & 96 & 2 & 94 & & \\
\hline \multicolumn{6}{|l|}{$\begin{array}{l}\text { Nature of } \\
\text { marriage }\end{array}$} \\
\hline Consanguineous & 256 & 8 & 248 & 0.01 & 0.937 \\
\hline \multicolumn{6}{|l|}{ Consanguineous } \\
\hline Parity & & & & & \\
\hline 1 & 392 & 11 & 381 & & \\
\hline $2-4$ & 571 & 15 & 556 & 0.118 & 0.943 \\
\hline $5+$ & 470 & 14 & 456 & & \\
\hline $\begin{array}{c}\text { Booking status of } \\
\text { pregnancy } \\
\text { Booked } \\
\text { Unbooked }\end{array}$ & $\begin{array}{c}1386 \\
65\end{array}$ & $\begin{array}{c}40 \\
1\end{array}$ & $\begin{array}{c}1346 \\
64\end{array}$ & 0.07 & 1.00 \\
\hline $\begin{array}{c}\text { Age of husband } \\
\text { (Years) } \\
20-34 \\
35-39 \\
40 \text { and above } \\
\end{array}$ & $\begin{array}{l}498 \\
306 \\
580\end{array}$ & $\begin{array}{r}12 \\
9 \\
18\end{array}$ & $\begin{array}{l}486 \\
297 \\
562\end{array}$ & 0.493 & 0.782 \\
\hline
\end{tabular}

Table 6 , Table 7 and Table 8 respectively present the results of the bivariate analysis of socio-demographic characteristics of neonates' mothers, peri-pregnancy characteristics of neonate's mothers, and characteristics of the neonates in the study in relation to the birth of a child with a congenital malformation. Only birth weight showed a significant association $(p=0.003)$ with being born with a 
congenital malformation, as children who weighed less than $2.5 \mathrm{~kg}$ at birth, had a higher prevalence of congenital malformation $(8 / 98 ; 8.16 \%)$ than those who weighed $2.5 \mathrm{~kg}-$ $4.0 \mathrm{~kg}$ at birth $(29 / 1196 ; 2.42 \%)$ and those who weighed more than $4.0 \mathrm{~kg}$ at birth $(0 / 27 ; 0 \%)$.

Multivariate analysis of the data is depicted in Table 9 which presents the adjusted odds ratios and 95 percent confidence intervals for being born with a congenital abnormality, based on the result of a binary logistic regression analysis done using age of mother, nature of parents' marriage, mother's parity, gestational age and birth weight as independent variables.

The findings of this model also showed that birth weight of the neonates was an important and significant predictor of being born with a congenital abnormality [OR $=0.374 ;(95 \%$ CI $0.196-0.711) \mathrm{p}=0.003]$. Thus birth weight has a significant but negative association with the likelihood of being born with a congenital abnormality

Table 7. Peri-Pregnancy characteristics of neonates' mothers in relation to birth of a child with a congenital malformation

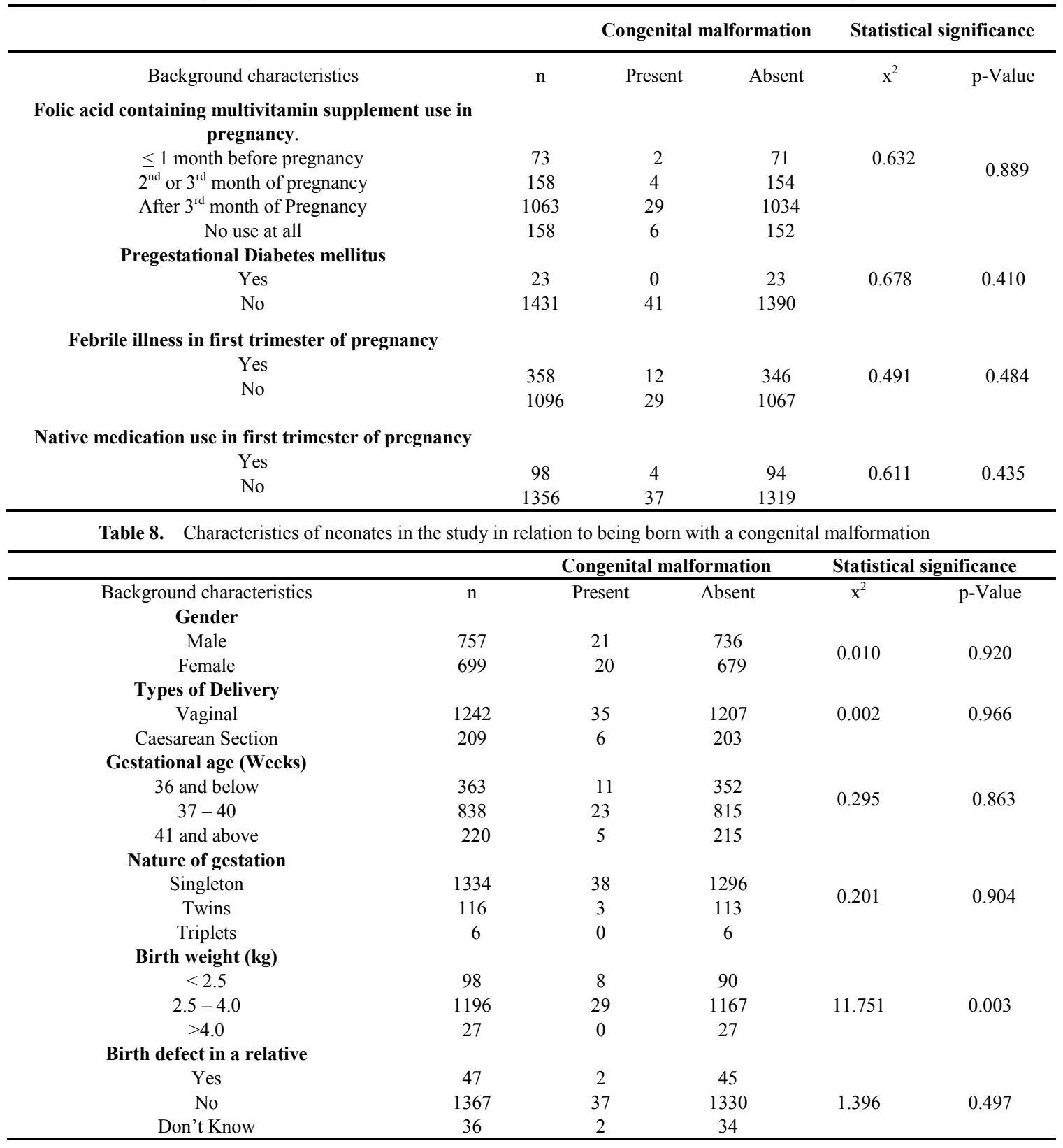


Table 9. Multivariate analysis of congenital malformations and other birth characteristics

\begin{tabular}{cccc}
\hline Explanatory variable & Odds Ratio & p-Value & 95\% CI (for odds ratio) \\
\hline $\begin{array}{c}\text { Age of Mother } \\
\text { Nature of Marriage } \\
\text { Consanguineous } \\
\text { Non-Consanguineous } \\
\text { Mother's parity }\end{array}$ & 1.044 & 0.284 & 0.965 \\
$\begin{array}{c}\text { Gestational age (weeks) } \\
\text { Birth weight (kg) }\end{array}$ & - & - & - \\
\hline
\end{tabular}

\section{Discussion}

Birth defects are an important cause of morbidity and mortality among children worldwide, thus making them a relevant public health concern. Congenital abnormalities are believed to arise from genetic causes in about $10-20 \%$ of cases, environmental causes in $10-20 \%$ of cases, and $60-80 \%$ are attributed to unknown factors $[3,8]$. It thus follows that birth defects can be categorized as those of a simple genetic origin (monogenic); or those due to interactions between multiple genetic and non-genetic, usually undefined factors (multifactorial), those associated with chromosomal abnormalities, those attributed to discrete environmental factors as the major causes, and all others with no recognized cause $[2,14]$.

The overall prevalence of birth defects in a given population, tells how many children in that population were born with at least one congenital abnormality. Worldwide surveys have shown that birth prevalence of congenital abnormalities varies greatly from country to country and even within the same country among regions, and this may be attributed to one or more factors such as the design of the study (hospital based or population based, prospective or retrospective), definitions, classifications and inclusion criteria used, end-point of the detection period, type of surveillance system and completeness of patient ascertainment, etiological heterogeneity of malformations, accuracy of diagnosis, prenatal screening policies, the extent of selective termination of affected pregnancies, the gestational age at which these are included in monitoring reports, the extent to which the terminations and notified, social, racial, ecological and economical influences $[2,15,16]$. As a consequence of all these factors, estimates of birth prevalence vary from place to place and thus make comparison of rates among studies difficult and probably not very informative [2,17]. However, apart from a small number of specific anomalies, any differences in prevalence are thought largely to be due to methodological difference rather than true difference in underlying population incidence [17].

The prevalence of congenital malformations in this study was 28.15 per 1000 live births. This figure is lower than the $6.9 \%$ reported in neonates by Bakare et al., in South western Nigeria [18]. It is however higher than the figure $(0.75 \%)$ reported from a hospital based study in neonates by Eluwa et al., in Cross River state of Southern Nigeria [19]. Birth prevalence of congenital anomalies varies appreciably from country to country, being as low as $1.07 \%$ in Japan and as high as $4.3 \%$ in Taiwan [16]. The prevalence of congenital anomalies found in this study is comparable to studies from other countries $[2,6,7,16]$. One of the reasons to explain this variation of prevalence figure could be that some degree of selection bias was probably in effect because the study was conducted in 3 major hospitals in the Kano metropolis of North Western Nigeria, which also receive referrals of high risk pregnancies from peripheral hospitals in the region. The exact number of such referrals as well as the number of pregnancies with fetal malformations diagnose elsewhere and referred to these hospitals for management was not assessed by this study. It is also worthy of note to mention that the rates reported in this study might have underestimated the prevalence of birth defects in the region as not all congenital anomalies could be detected at birth or shortly thereafter because of the lack of cytogenetic and teratology investigations or autopsies for still birth and neonatal deaths [15].

Longitudinal cohort studies with special follow up examination provide high incidence figures for congenital anomalies as contrasted to studies based on information from hospital data, because it collects valid information on late manifestation of congenital malformations [20].

The highest frequency of congenital malformations reported in this study involved the Central Nervous System (CNS) and genitourinary system (GU), followed by dermatological system, gastrointestinal system (GIT), musculoskeletal system, and the mouth. CNS anomalies which occurred both as single system and multiple system malformations are considered the most common anomalies in this study. This finding is similar to what has been reported from Cross Rivers State in the South of Nigeria [19], and from Jos in the North central region of Nigeria [21], as well as workers from other parts of the world $[15,20,22]$. The finding is however at variance with the report of Bakare et al., from South Western Nigeria and that of some other workers from outside the region $[2,14,16,18]$. The data however show that the frequency of anomalies in other systems differs in different studies done from various regions of the world [1, $3,8]$.

Observational studies have shown that maternal use of at 
least 400 micrograms of folic acid alone or in multivitamin supplements daily starting at least one month before conception and through the first trimester of pregnancy is effective in preventing both the occurrence and recurrence of neural tube defects $[2,23,24]$. Periconceptional use of folic acid alone, or in multivitamins supplements have also been shown to reduce the occurrence of some other congenital abnormalities [25,26,27].

Consanguineous marriages are believed to be important in contributing to the risk of being born with a congenital abnormality [28 -31]. It has been documented that the risk of a child having a recessively inherited condition is higher if the parents are related, and the more closely related the parents are, the higher the risk $[1,30]$. High rates of consanguinity ranging between $25-60 \%$ of all marriages have been reported for Muslim Arab countries [2,20,29]. Majority of the mothers in this study $(95.11 \%)$ were from Muslim homes, and the consanguinity rate in the study was $17.83 \%$ the rate of malformation was $3.13 \%$ and $2.80 \%$ in consanguineous and non-consanguineous marriages respectively. Although, the prevalence of anomalies was higher in consanguineous marriages than non-consanguineous marriages, this was however not statistically significant. This finding is in agreement with the finding of Tayebi et al.[32], but is at variance with the results from the study by Francine et al.[16 ],who found a statistically significant relationship between parental consanguinity and being born with a congenital abnormality.

In this study, females were more affected with congenital anomalies $(2.86 \%)$ than males $(2.77 \%)$. This difference was however not statistically significant. Other workers have reported a male excess for congenital anomalies [20,33]. This finding has raised some speculations i.e. either females are afflicted with a relatively more minor abnormality which they survive with, or they suffer more fatal anomalies [30]. It is thus recommended that sex distribution should be studied in every congenital malformation separately and not in the whole group, as it is evident from literature that there are large reported variations in patterns of congenital malformations involving different body system [20,30].

Multi-parity was associated with increased prevalence of congenital malformations in this study. Women who had 5 or more children had the highest prevalence of births with a congenital malformation ( $2.98 \%$ ). The relationship between parity and the birth of a child with a birth defect was however, not statistically significant. Shawky and Sadik had earlier noted an association between multi-parity and an increase in the prevalence of congenital malformations [20]. Muga et al., had also noted in their study that among the babies with a CNS malformation, that birth order "4" contributed $55.2 \%$ of the cases [7]. At variance with these observations however is the report by Tomatir et al., who showed that in their series, $78.1 \%$ of the mothers who had given birth to a child with a congenital anomaly, were experiencing their first or second live birth [8].

Findings from this study reveal that the prevalence of birth defects was higher in the offspring of women who gave a history of having a febrile illness in the first trimester of pregnancy $(3.35 \%)$ than those who did not have $(2.65 \%)$. The association between the birth of a child with a congenital anomaly and having a febrile illness in the first trimester of pregnancy was however not statistically significant. It has been known for about 100 years now that malformations could be induced in various animal species by exposing the mother to high body temperatures during critical periods of gestation $[34,35,36]$. Although human data are inconclusive and often conflicting, it is believed that the threshold of effect in many species begins at about $1.5^{\circ} \mathrm{C}$ over normal core body temperature [34, 35]. Defects of the CNS, craniofacial development including clefts, the axial and appendicle skeleton, the body wall, teeth, and heart are commonly found in various animal species, and nearly all these defects have been found in human epidemiological studies following maternal fever or hyperthermia during pregnancy [36].

Data from this study reveal that $9.76 \%$ of the mothers of the neonates with congenital anomalies had a positive history of use of native medication (non-alcohol, non-orthodox) in the first trimester of pregnancy. The prevalence of congenital anomalies was higher $(4.08 \%)$ in the offspring of mothers who had used native medication in the first trimester of pregnancy than in those who had not $(2.73 \%)$. This was however, not statistically significant. Drugs taken by pregnant women can cross the placenta, alter its oxygen transport function by constricting blood vessels, and affect the fetus by acting directly on it, causing damage, abnormal development, teratogenesis or death [20]. Francine et al., documented in their series that maternal drug intake during pregnancy was positively associated with congenital malformation in the offspring [16].

In this study, a high prevalence of birth defects $(8.16 \%)$ was observed in children whose birth weight was less than $2.5 \mathrm{~kg}$, than in those with a birth weight of $4.0 \mathrm{~kg}$ and above $(0 \%)$. This finding was statistically significant $(\mathrm{p}=0.003)$. Multivariate analysis also revealed that birth weight was a significant and important predictor of being born with a congenital abnormality among the neonates in the study. A high prevalence of birth defects was also noted in this study for preterm (less than 37 weeks gestational age) neonates than for term (37 weeks gestational age or more) neonates. This finding was however not statistically significant. A high prevalence of birth defects have also been previously reported in other studies among infants with low or very low birth weight as well as in prematures $[16,37,38,39]$. More than 20 million low birth weight (LBW) infants are born globally each year, consisting $17 \%$ of all births in developing countries, which is more than the $7 \%$ rate in industrialized nations [40].

Low birth weight babies basically constitute two groups of babies- those born before 37 completed weeks (preterms) and those born after 37 completed weeks [small for gestational age (SGA)], with the causes and mechanism 
involved in LBW being different for premature infants and SGA infants and thus requiring different interventions for prevention [41]. The relationship between growth restriction and malformations may be explained by either the growth restriction as primary and predisposing the fetus to malformations, or as secondary to the presence of malformations, or by coexisting with a malformation due to common etiologic factors [37]. Low birth weight can be caused by various perinatal problems, most frequently by low gestational age [40]. The prevalence of low gestational age (less than 37 weeks gestational age) in this study was $25.55 \%$.

This study had some limitations in that it sought to detect only external (overt) congenital anomalies in neonates within the first 48 hours of birth, relying only on clinical examinations to make a diagnosis. Also neither cytogenetic analysis nor autopsies for stillbirths were done. It has been documented that a specific diagnosis may not be reached for $30-60 \%$ of infants with malformations and that diagnosis is not always apparent in the new born period [2]. Notwithstanding the noted limitations, this study provides some information on the magnitude and spectrum of congenital malformations diagnosed soon after birth in neonates in the Kano metropolis of North Western Nigeria.

\section{Conclusions}

Data from this study show that CNS anomalies which occurred both as single system and multiple system anomalies, were the most common congenital malformations noted in the study population. Also the prevalence of low gestational age (prematurity) in the study was $25.55 \%$. Given that congenital anomalies are a major cause of morbidity and mortality in developing countries, and that a positive association exist between low birth weight, prematurity and congenital malformations, emphasis ought to be placed on primary prevention of congenital anomalies, targeting those obstetric factors that increase the incidence of prematurity and neural tube defects in the offspring by encouraging routine and comprehensive prenatal care for all expectant mothers, periconceptional use of folic acid containing multivitamin preparations, the avoidance of known teratogens and probable teratogenic agents, as well as preventing and treating disease such as malaria and HIV/AIDs.

\section{Conflict of Interest}

None Declared.

\section{REFERENCES}

[1] AL- Gazali LI, Dawodu AH, Sabarinathan K, Varghese M.
The profile of major congenital abnormalities in the United Arab Emirates (UAE) population. Journal of Medical Genetics 1995; 32:7-13.

[2] Sawardekar KP. Profile of major congenital malformations at Nizwa Hospital, Oman: 10- year review. Journal of Paediatrics and Child Health 2005; 41: 323-330.

[3] Sallout BI, Al Hoshan MS, Attyyaa RA, Al Suleimet AA. Antenatal diagnosis, prevalence and outcome of major congenital anomalies in Saudi Arabia :a hospital based study. Annals of Saudi Medicine 2008; 28:272-276.

[4] Ochieng J, Kiryowa H,Munabi I, Ibinga CBR. Prevalence, nature and characteristics of external congenital anomalies at Mulago Hospital. East and Central African Journal of Surgery 2011; 16: 26-30.

[5] Kingston HM. ABC of Clinical Genetics. $3^{\text {rd }}$ ed. BMJ Books, London 2002.

[6] Dastgiri S, Stone DH, Le-Ha C, Gilmour WH. Prevalence and secular trend of congenital anomalies in Glasgow, UK. Archives of Diseases in Childhood 2002; 86:257-263.

[7] Muga RO, Mumah SCJ, Juma PA. Congenital malformations among newborns in Kenya. African Journal of Food Agriculture Nutrition and Development 2009; 9:814-829.

[8] Tomatir AG, Demirhan H, Sorkun HC, Koksal A, Ozerden F, Cilengir N. Major congenital anomalies: a five year retrospective regional study in Turkey. Genetics and Molecular Research 2009; 8:19-27.

[9] World Health Organization. Sixty- third World Health Assembly Provisional Agenda item 11.7. A63/10. Geneva 2010 .

[10] Penchaszadeh VB. Preventing congenital anomalies in developing countries. Community genetics 2002; 5:61-69.

[11] Walden RV, Taylor SC, Hansen NI, Poole WK, Stoll BJ, Abuelo D, Vohr BR. Major congenital anomalies place Extremely Low Birth Weight infants at higher risk for poor growth and development outcomes. Pediatrics 2007; 120:e1-e8.

[12] Abdi-Rad I, Khoshkalam M, Farrokh- Islam Lou HR. The prevalence at birth of overt congenital anomalies in Urmia, Northwestern Iran. Achieves of Iranian Medicine 2008; 11:148-151.

[13] Delport SD, Christianson AL, Van den Berg HJS, Wolmarans L, Gericke GS. Congenital anomalies in black South African live born neonates at an urban academic hospital. South African Medical Journal 1995; 85:11-15.

[14] Queisser- Luft A, Spranger J. Congenital malformations Deutsches Arzteblatt 2006; 103: 2464-2471.

[15] Dastgiri S, Imani S, Kalankesh L, Barzegar M, Heidarzadeh M. Congenital anomalies in lran: a cross sectional study on 1574 cases in the North - west of country. Child: Care , Health and Development 2007;33:257-261.

[16] Francine R, Pascale S, Aline H. Congenital anomalies: Prevalence and risk factors. Universal Journal of Public Health 2014; 2: 58- 63.

[17] Kurinczuk JJ, Hollowell J, Boyd PA, Oakley L, BrockleHurst P, Gray R. Inequalities in infant mortality project briefing paper 4 . The contribution of congenital anomalies to 
infant mortality. Oxford: National Epidemiology Unit 2010. Available at www.npeu.ox.ac.uk/infantmortality. Accessed 12th April, 2013.

[18] Bakare TIB, Sowande OA, Adejuyigbe OO, Chinda JY, Usang UE. Epidemiology of external birth defects in neonates in South Western Nigeria. African Journal Of Paediatric Surgery 2009; 6:28 30.

[19] Eluwa MA, Aneosong SA, Akpantah AO, Ekong MB, Asuquo OR, Ekanem TB. Congenital malformations recorded in four hospitals in central part of Cross River State, Nigeria. International Journal of Pharmaceutical Science Invention $2013 ; 2: 27-30$.

[20] Shawky RM, Sadik DI. Congenital malformations prevalent among Egyptian children and associated risk factors. The Egyptian Journal of Medical Human Genetics 2011; 12: 69-78.

[21] Danborno B, Danladi SB. The incidence of central nervous system congenital anomalies in Jos, Nigeria. Journal of Research in Bioscience 2008; 4:98-102.

[22] Swain S, Agrawal A, Bhatia BD. Congenital malformations at birth. India Pediatrics 1994; 31:1187-1191.

[23] Ying Wu D, Brat G, Milla G, Kim J. Knowledge and use of folic acid for prevention of birth defects amongst Honduran women. Reproductive Toxicology 2007; 23:600-606.

[24] Koren G, Goh YI, Klieger C. Folic acid the right dose. Canadian Family Physician 2008; 54:1545-1547.

[25] Hall J, Solehdin F. Folic acid for the prevention of congenital anomalies. European Journal of Pediatrics 1998; 157:445-450.

[26] Czeizel AE. Birth defects are preventable. International Journal of Medical Sciences 2005; 2:19-92.

[27] Bailey LB, Berry RJ. Folic acid supplementation and the occurrence of congenital heart defects, orofacial clefts, multiple birth, and miscarriages. American Journal of Clinical Nutrition 2005; 81:1213S-1217S.

[28] Narchi H, Kulaylat N. Congenital malformation: Are they more prevalent in populations with a high incidence of consanguineous marriages. Annals of Saudi Medicine 1997; 17:254-256.

[29] Al-Gazali L, Hamamy H, Al- Arrayad S. Genetic disorders in the Arab world. British Medical Journal 2006; 333:831-834.

[30] Fida NM, Al- Aama J, Nichols W, Alqahtani M. A prospective study of congenital malformations among live born neonates at a University hospital in Western Saudi Arabia. Saudi Medical Journal 2007; 28:1367-1373.

[31] Al Bu Ali WH, Balaha MH, Al Moghannum MS, Hashim I. Risk factors and birth prevalence of birth defects and inborn errors of metabolism in Al Ahsa, Saudi Arabia. Pan African Medical journal 2011; 8: 14.

[32] Tayebi N, Yazdani K, Naghshin N. The prevalence of congenital malformation and its correlation with consanguineous marriages. Oman Medical Journal 2010; 25 : 37- 40 .

[33] Sokal R, Tata LJ, Fleming KM. Sex prevalence of major congenital anomalies in the United Kingdom: A national population based study and international comparison meta analysis. Birth Defects Research ( Part A) 2014; 100: 79-91.

[34] Graham JM, Edwards MJ, Edwards MJ. Teratogen update: Gestational effects of maternal hyperthermia due to febrile illness and resultant patterns of defecst in humans. Teratology 1998;58: 209-221.

[35] Moretti ME, Bar-Oz B, Fried S, Koren G. Maternal hyperthermia and the risk for neural tube defects in offspring: Systematic review and meta-analysis. Epidemiology 2005; 16: 216-219.

[36] Edwards MJ. Review: Hyperthermia and fever during pregnancy. Birth defects research (Part A), Clinical and Molecular Teratology 2006; 76: 507-516.

[37] Melve KK, Skjaerven R. Families with birth defects: Is birth weight of non- malformed siblings affected? American Journal of Epidemiology 2002; 155: 932- 940.

[38] Fatema K, Begum F, Akter N, Zaman SMM. Major congenital malformations among the nemborns in BSMMU hospital. Bangladesh Medical Journal 2011; 40:7-12.

[39] Adams - Chapman I ,Hansen NI, Shankaran S, Bell EF, Boghossian NS, Murray JC, et al. Ten year review of major birth defects in VLBW infants Pediatrics 2013;132:49-61.

[40] Moraes AB, Zanini RV, Riboldi J, Giugliani ERJ. Risk factors for low birth weight in Rio Grande do Sul State, Brazil: Classical and multilevel analysis. Cadernos de Saude Publica Rio de Janeiro 2012; 28; 2293-2305.

[41] Ugwu R, Eneh A. The population of low birth weight babies due to Small for Gestational Age (SGA) and prematurity in Port Harcourt, South-South Nigeria- Changing trends. The Internet Journal of Pediatrics and Neonatology 2010;13:1. 